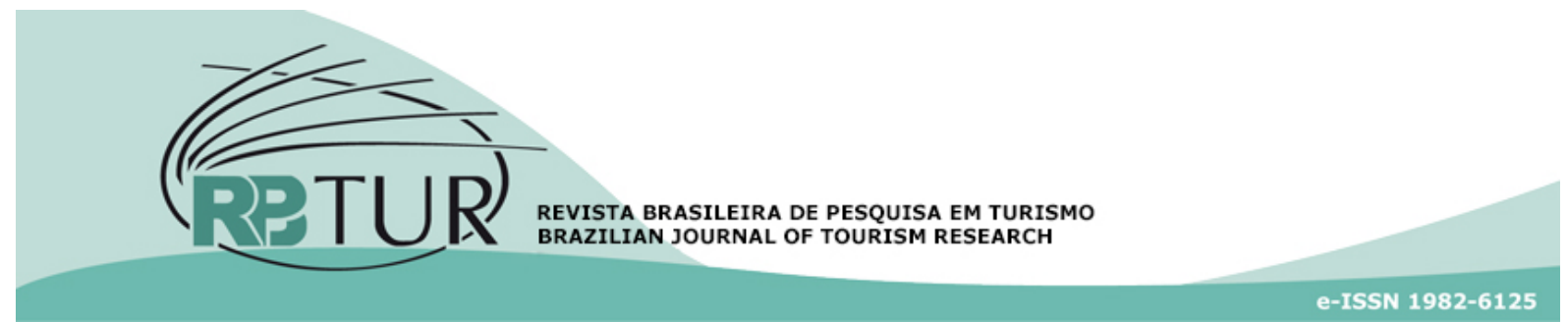

Artigo

DOI: http://dx.doi.org/10.7784/rbtur.v11i1.1164

\title{
Atributos determinantes na decisão de compra e satisfação dos clientes: um estudo em estabelecimentos que comercializam comida de rua
}

\author{
Determinants attributes in purchase decision: a study in \\ establishments commercialize street food
}

\section{Atributos determinantes de decisiones em la compra y la satisfacción del cliente: un estudio en los establecimientos que comercializam alimento en la calle}

\section{Hannah Nicchio Loriato ${ }^{1}$ Anderson Soncini Pelissari ${ }^{2}$}

Resumo: Os atributos de um produto podem variar substancialmente na importância que eles têm para diferentes consumidores, assim a partir da concepção de que há diferentes graus de importância em relação aos atributos e que essa importância influência na decisão de compra. Este artigo tem como objetivo identificar quais atributos são determinantes para os consumidores na tomada de decisão de compra em estabelecimentos que comercializam comida de rua. Trata-se de um estudo de natureza qualitativa e quantitativa. Na fase qualitativa foi realizada uma entrevista semiestruturada com 16 clientes e analisada por meio da análise de conteúdo. Para o levantamento dos dados na fase quantitativa foi realizado um survey, com a aplicação de 200 questionários. A análise desta fase quantitativa foi realizada com a utilização do Excel e do SPSS, com emprego de técnicas de estatística multivariada. Os resultados indicaram que o serviço oferecido é o constructo considerado determinante para a decisão de compra dos clientes. Esta pesquisa propicia a ampliação desse escopo de pesquisas no país, bem como contribui para os empreendedores no setor de street food que buscam estratégias para se manterem firmes no mercado.

1 Universidade Federal do Espírito Santo. (UFES), Brasília, DF, Brasil. Concepção e desenho do trabalho científico, formulação de ideias, coleta dos dados, análise dos dados, preparação do artigo científico.

2 Universidade Federal do Espírito Santo. (UFES), Brasília, DF, Brasil. Análise e ajuste do desenho do trabalho científico, análise e ajuste na formulação de ideias, análise e ajuste para a coleta dos dados, ajuste e adequação na análise dos dados, análise, ajuste e adequação do artigo científico.

Artigo recebido em: 02/05/2016. Artigo aprovado em: 13/10/2016. 
Palavras chave: Importância do Atributo. Atributo Determinante. Decisão de Compra. Satisfação. Comida de Rua.

Abstract: The attributes of a product can vary greatly in the importance they have for different consumers, and from the idea that there are different degrees of importance in relation to the attributes and importance that influence the buying decision. The purpose of this study is to identify which attributes are crucial for consumers in making buying decisions in establishments that sell street food. It is a study of both qualitative and quantitative nature. In the qualitative phase was conducted semi-structured interviews with 16 customers and analyzed using content analysis.It was carried out one survey, applying 200 questionnaires, to survey data for quantitative phase. The analysis of this quantitative phase was carried out using Excel and SPSS, with the use of multivariate statistical techniques. The results indicated that the service offered is the construct considered crucial to the customers' buying decision. In addition, this study enables the spread of this research scope in the country and contributes to the entrepreneurs in the street food sector seeking strategies to keep themselves firmly in the market.

Keywords: Importance of the attribute. Determinant attribute. Buying decision. Satisfaction. Street food.

Resumen: Los atributos de un producto pueden variar mucho en la importancia que tienen para diferentes consumidores, y de la idea de que hay diferentes grados de importancia en relación con los atributos y la importancia que influyen en la decisión de compra. Este artículo tiene como objetivo identificar los atributos que son cruciales para los consumidores en el tomado de decisión de compra en establecimientos que venden comida en la calle. Se trata de un estudio de naturaleza cualitativa y cuantitativa. En la fase cualitativa fue realizada una entrevista semiestructurada con 16 clientes y analizados por meio del análisis de contenido. Para el estudio de los datos en la fase cuantitativa fue realizada una encuesta, mediante la aplicación de 200 cuestionarios. El análisis desta fase fue realizada con el uso de Excel y SPSS, con el uso de técnicas estadísticas multivariantes. Los resultados indicaron que el servicio prestado és el constructo considerado determinante en la decisión de compra de los clientes. Esta investigación propicia el aumento de este ámbito de investigación en el país, así como contribuye a los emprendedores en el campo de la comida en la calle buscando estrategias para permanecer firme en el mercado.

Palavras clave: Importancia del atributo. Atributo determinante. Decisión de Compra. Satisfacción. Comida en la calle.

\section{INTRODUÇÃO}

O consumo permeia a vida de todos na sociedade atual (Peter \& Olson, 2009)."Ser consumidor é ser humano" (Karsaklian, 2004, p.13). Neste cenário, torna-se inquestionável a importância dada aos consumidores e aos clientes, uma vez que as empresas, em meio à concorrência, buscam diversificar a forma como oferecem os produtos e serviços que os consumidores precisam, a fim de torná-los leais (Peter \& Olson, 2009).

Peter e Olson (2009) afirmam que o consumidor é dinâmico, bem como o ambiente no qual está imerso, onde ocorrem mudanças constantemente. Tais transformações têm afetado, entre vários outros, o setor de alimentação (Lima Filho et. al., 2004).

A alimentação limitava-se ao cenário doméstico; era responsabilidade da mulher cozinhar para alimentar a família. Entretanto ocorreram mudanças na sociedade que interferiram diretamente nesses hábitos (Diez Garcia, 1999), com destaque para o crescimento da frequência da alimentação fora do domicílio (Leal, 2010; Sanches \& Salay, 2011). Em 2013, 32,9\% do consumo alimentício da população brasileira foi realizado fora do $\operatorname{lar}(A B I A, 2013)$. Esse fenômeno deve-se ao fato das pessoas substituírem o consumo de alimentos tradicionais poralimentos de fácil e rápido 
preparo (Schlindwein \& Kassouf, 2007).

As comidas de rua surgem, nesse contexto, como uma opção viável financeiramente ao oferecer comida diversificada e pronta para o consumo imediato, supre, assim, essa crescente demanda de consumo por uma alimentação prática (Cardoso, Santos \& Silva, 2009). Esse tipo de empreendimento tornou-se comum nas capitais brasileiras e também no exterior (Cardoso, Santos \& Silva, 2009). Cerca de 2,5 bilhões de pessoas em diversos países consomem diariamente comida de rua (FAO, 2011).

Pigatto e Nishimura (2012) afirmam que vendedores de comida de rua atuam em um mercado extremamente competitivo, devido ao fato do serviço de alimentação possuir grande variedade de oferta, além de não haver barreiras de entrada, por não necessitar de alto investimento inicial e oferecer retorno financeiro em curto prazo (WHO, 1996; FAO, 2011). Neste contexto de competitividade, um fator crucial para obter vantagem, adaptar-se às novas exigências, de modo a garantir a sobrevivência e longevidade no mercado é avaliar quais atributos presentes nos produtos ou serviços geram a satisfação dos clientes (Pelissari et al., 2011; Machado, Queiroz \& Martins, 2006).

Diante do contexto exposto, apresenta-se o seguinte problema: Quais são os atributos determinantes, na tomada de decisão de compra de consumidores, em uma Praça de Vitória/ES que comercializa comida de rua? Pretende-se ainda, para que obter a resposta deste problema, hierarquizar os atributos conforme a classificação proposta por Alpert (1971) e desenvolver uma escala de mensuração dos atributos no contexto de comida de rua.

Assim, a hipótese teórica a ser testada neste estudo foi: $H$ : há diferença no grau de importância, atribuído pelos clientes, aos atributos. Ao testar essa hipótese, é possível classificar os atributos quanto ao seu grau de importância, conforme tipologia de Alpert (1971), que representa um dos objetivos a ser atingido nesta pesquisa.

Os resultados desta pesquisa corroboram para ampliar o escopo de pesquisa no país referente a comida de rua, bem como é relevante para que os empreendedores estabeleçam estratégias para alocar seus recursos de forma assertiva, melhorarem o posicionamento no mercado, obterem melhores resultados financeiros, atrair novos clientes e mantê-los satisfeitos.

\section{REFERENCIAL TEÓRICO}

\subsection{A Importância Dos Atributos Na Decisão De Compra}

Atento às necessidades dos consumidores, o empresário moderno mostra um interesse crescente na investigação do processo de tomada de decisão do consumidor, de modo a entender como um indivíduo toma suas decisões de compra em um ambiente competitivo (Bandara, 2014).

Vieira e Slongo (2008) articulam que cada objeto de consumo pode ser considerado pelo consumidor como um conjunto de atributos que possuem peso no momento de decisão de compra. De tal modo, conhecer os atributos e seus valores passa a ser considerado um forte aspecto, 
responsável pela decisão de compra dos bens (Vieira \& Slongo, 2008), uma vez que é comum os consumidores definirem um produto de acordo com os atributos que este apresenta e, a partir da sua percepção, é tomada a decisão de compra (De Moura, Nogueira \& Gouvêa, 2012).

De Moura, Nogueira e Gouvêa (2012, p.77) explicam que "[...] um atributo pode ser entendido como uma característica, componente ou função que um produto desempenha $[. .$.$] ", o que estimula a decisão$ de compra por parte do consumidor. Hawkins, Mothersbaugh e Best (2007) destacam a escolha baseada nos atributos como uma das formas de avaliar as alternativas para efetivar uma compra.

Nesse contexto, há um consenso na literatura no qual autores (Alpert, 1971; Mowen \& Minor, 2003; Engel, Blackwell \& Miniard, 2005; Zeithaml, 1988; Taplin, 2012) articulam que os atributos diferem consideravelmente na importância que possuem para os consumidores, ou seja, os atributos de um produto podem variar substancialmente na importância que eles têm para diferentes consumidores, de acordo com as características específicas de cada indivíduo (Engel, Blackwell \& Miniard, 2005). Alpert (1971), a partir da concepção de que há diferentes graus de importância em relação aos atributos e que essa importância influencia na decisão de compra, propõe a seguinte classificação dos atributos:

- Atributos Salientes: são aqueles atributos os quais os consumidores conseguem perceber como presentes em determinado produto, marca, empresa ou instituição, mas não interferem na determinação do processo de compra do produto (Alpert, 1971). McMillan e McGrath (1996) explicam que esses atributos somente terão influência direta na compra como fator de desempate, ou seja, se todas as demais condições forem equivalentes em relação ao produto que está sendo analisado.

- Atributos Importantes: são aqueles percebidos por um determinado grupo de consumidores como importantes no ato da compra, porém não a determinam (ALPERT, 1971). São aspectos que por si só não são capazes de determinar a escolha de compra e, portanto, não influenciam nem agregam valor pelo fato de estarem presentes em uma categoria similar de produtos (Alpert, 1971). Assim, muitos não consideram os atributos importantes por perceberem sua presença em todos os produtos de uma determinada classe (Alpert, 1971).

- Atributos Determinantes: para Alpert (1971) estes atributos possuem grande importância para o consumidor, por isso podem fazer com que este tome a decisão de compra. Assim, são percebidos como a melhor opção para maximizar a satisfação e atingir os valores almejados pelo consumidor. Efetivamente são capazes de direcionar a escolha. Os atributos determinantes apresentam-se para o consumidor como a melhor possibilidade de resposta da satisfação de seus desejos em determinado produto ou marca (Alpert, 1971). 
Essa pesquisa se baseará na classificação do Alpert (1971) quanto aos diferentes graus de importância dos atributos, destacando, em especial, os atributos determinantes identificados na comercialização de comida de rua.

O próximo tópico concentra-se em apresentar aspectos relacionados à alimentação fora do lar, que consiste em um hábito presente no cotidiano dos indivíduos, no qual se insere uma gama de empreendimentos neste atrativo mercado, como é o caso das comidas de rua.

\subsection{Comida de Rua: Uma Alternativa de Alimentação Fora do Lar}

$\mathrm{Na}$ contemporaneidade há transformações relacionadas à estrutura produtiva que atuam consideravelmente no cotidiano dos indivíduos (Fantinel, Teixeira \& Ghizzo, 2011). Aspectos como a inserção das mulheres no mercado de trabalho, excesso de trabalho, ritmo pesado de estudos, trânsito congestionado, entre outros, tornam o tempo um elemento escasso na vida das pessoas, o que consequentemente ocasiona mudanças nos hábitos de pessoas e de grupos, inclusive no que diz respeito à alimentação. Nesse contexto, a população busca serviços de alimentação fora de casa, por serem adequados às suas necessidades físico-alimentícias ao tempo que têm disponível (Fantinel, Teixeira \& Ghizzo, 2011; Diez Garcia, 1999, Lambert et al., 2005, Bezerra, Souza \& Pereira, 2013; Schlindwein \& Silva, 2010).

O consumo de alimentos fora do domicílio torna-se cada vez mais comum na vida das pessoas, sendo realizado frequentemente. Trata-se de um fenômeno mundial, presente tanto em países desenvolvidos quanto em países em desenvolvimento (Bezerra, Souza \& Pereira, 2013; Fantinel, Teixeira \& Ghizzo, 2011; Edwards, Hartwell \& Brown, 2013; Nordström \& Thunström, 2015). A tendência é que continuem surgindo novos nichos do setor de alimentação fora de casa (Liu, Kasteridis \& Yen, 2013; Mauro, 2013).

Um exemplo de novas tendências na alimentação fora dos limites domiciliares é o surgimento de um novo segmento originado do setor de comida de rua, são os chamados food trucks (caminhões de comida), que consistem em pequenos caminhões ou vans especializadas em servir diversos tipos de comida; são praticamente restaurantes móveis (Piza, 2014). Em São Paulo esse segmento tem ganhado força, principalmente após a regularização da atividade, com a aprovação do projeto de lei que regulamenta a venda de comida de rua na cidade (Simon, 2013). As comidas de rua ganham destaque ao representarem uma opção de alimentação que dá suporte ao desenvolvimento do hábito de comer fora de casa (Castro, 2008), compreendendo uma alternativa viável para grande parte da população (Santos et al., 2012; Cardoso, Santos \& Silva, 2009).

Estudos realizados pelo Instituto Americano IBISWorld (2014) apontam que os vendedores de comida de rua estão em uma fase de crescimento. Eles foram capazes de se esquivar de recessões e oferecer produtos novos capazes de atrair uma clientela mais diversificada (IBISWorld, 2014). Trata-se de alimentos variados e atraentes para os turistas, uma vez que estão presentes as 
principais comidas regionais locais, apreciadas pelo seu sabor (WHO, 1996; Rane, 2011; Newman \& Burnet, 2013; Pigatto \& Nishimura, 2012; Samapundo et al., 2015). É ainda uma importante fonte de renda, pois proporciona subsistência para um grande número de trabalhadores, em especial nos países em desenvolvimento (Santos, 2011).

Esse tipo de alimentação compreende parte do cotidiano, com sua presença em locais próximos a áreas comerciais (Cardoso, Santos \& Silva, 2009), bem como instalações industriais e praças (Muyanja et al., 2011). Normalmente trata-se de locais onde há grande movimentação de pessoas, com clientela imediata e numerosa (Muyanja et al., 2011).

\section{ASPECTOS METODOLÓGICOS DA INVES- TIGAÇÃO}

Com o intuito de desvelar quais atributos são determinantes para os consumidores na tomada de decisão de compra em estabelecimentos que comercializam comidas de rua, esta pesquisa teve como unidade de análise uma praça localizada na cidade de Vitória/ES, a Praça Regina Frigeri Furno. Os objetos de pesquisa são os clientes que consomem nos estabelecimentos de comidas de rua que funcionam neste espaço.

Essa praça iniciou suas atividades na década de 1990. Atualmente, quem administra e regulariza o seu funcionamento é a Prefeitura Municipal de Vitória. A Praça faz parte do programa de "Feiras Comunitárias Regionais", criado pela Lei no 5.949, de 16 de julho de 2003. O espaço em que a praça funciona possui exposição e comercialização de produtos artesanais manufaturados, alimentação e brinquedos. 0 objetivo nesse espaço é fomentar o lazer local, a integração da comunidade e o comércio ordenado, respeitando os limites legais para sua instalação e funcionamento (Brasil, 2003).

A praça hoje é um local com grande variedade de alimentos comercializados com funcionamento ativo de, aproximadamente, 43 estandes com oferta de serviços de alimentação. Com funcionamento de quarta à sexta feira, no horário das $17 \mathrm{~h}$ às $23 \mathrm{~h}$. Nos dias de sexta é possível observar maior movimento, com grande número de pessoas.

Para responder à problemática proposta neste estudo, desenvolveram-se duas etapas de pesquisa: uma que utiliza métodos de natureza qualitativa exploratória-por se tratar de um tema pouco estudado e que, com muitas lacunas a serem preenchidas, inicialmente buscou-se desenvolver um estudo preliminar com a finalidade de adequar o instrumento de medida à realidade do contexto -e outra quantitativa de natureza descritiva-umavez que teve como principal finalidade descrever certas características de mercado específico e de grupos relevantes inerentes à pesquisa (Malhotra, 2006), o que possibilita estabelecer correlações entre variáveis (Vergara, 2011), conforme segue no próximo tópico.

\subsection{Etapa Qualitativa: Entrevista com os Clientes}

$\mathrm{Na}$ etapa qualitativa foram realizadas entrevistas individuais junto aos clientes que consomem comida de rua na praça analisada, com o objetivo de identificar os atributos 
determinantes na decisão de compra. Foram realizadas 16 entrevistas, observando o ponto de saturação das mesmas, divididas em dois dias diferentes de funcionamento dos estabelecimentos, 3 e 12 de junho de 2015.

Os dados foram estudados por meio de técnicas de análise de conteúdo, às quais consistem em "[...] um conjunto de técnicas de análise das comunicações, que utiliza procedimentos sistemáticos e objetivos de descrição do conteúdo das mensagens [...]", cujo interesse é nos ensinamentos que resultam do seu tratamento (Bardin, 1977, p. 38).

Feita esta análise, as respostas foram categorizadas (Bardin, 1977). As categorias identificadas nas entrevistas realizadas na fase qualitativa, juntamente com os atributos encontrados na literatura, serviram de base para identificar e definir os atributos que foram utilizados no questionário survey, utilizado na fase quantitativa desta pesquisa.

\subsection{Etapa Quantitativa: Levantamento (Survey)}

Nesta etapa, os dados primários foram obtidos por meio da técnica survey, ou seja, levantamento de dados que, segundo Hair et al. (2005), se trata de uma técnica que utiliza um questionário para reunir informações sobre uma população a partir de uma amostra significativa.

O questionário utilizado foi estruturado com perguntas fechadas, empregando a escala do tipo ordinal crescente composta por 06 pontos. Malhotra (2006) explica que a escala ordinal é uma escala de graduação, na qual é possível atribuir números a determina dos itens para indicar até que ponto possui uma característica, sendo possível então determinar se um item/objeto possui essa característica em maior ou menor grau. Nesta escala o grau de concordância cresce, conforme seja maior o número de pontos assinalados com declarações relativas à atitude que está sendo medida. Não foi considerado ponto neutro ou central, pois se pretendeu evitar a tendência central. Desejou-se que os clientes se posicionassem de forma definitiva positiva ou negativamente e não de forma neutra.

Essa definição foi baseada na teoria de Garland (1991), a qual afirma que pesquisadores, em especial da área de marketing, buscam respostas que assumam uma posição definitiva, sem categoria central. Garland (1991) defende que a categoria central pode distorcer resultados.

Antes da aplicação efetiva do questionário, com a finalidade de sanar os problemas na fase de levantamento (survey), foi executado um pré-teste com 10 sujeitos para verificar a clareza do questionário, a abrangência das perguntas, bem como a aceitabilidade das perguntas pelos entrevistados, fazendo as correções necessárias (Rea \& Parker, 2000).

Após os ajustes e conclusão do questionário survey foi iniciada a fase de coleta de dados. O levantamento ocorreu em duas semanas consecutivas, nos dias de quarta, quinta e sexta-feira (dias oficiais de funcionamento da praça), no mês de junho de 2015 (17, 18, 19, 24 e 26). É importante salientar que as datas para o levantamento dos dados foram escolhidas desprezando período de férias ou feriados, pois devido a esses aspectos poderiam ocorrer 
modificações no campo de estudo. Para o procedimento de tratamento dos dados foi realizada a tabulação e análise por meio da ferramenta Excel do software estatístico SPSS (Statistical Package for the Social Sciences).

Em relação à amostra, Malhotra (2006) orienta ainda que o tamanho considerado ideal para garantir uma robustez nas pesquisas que estimam tendências de mercado deve ser de 200 amostras. Outra forma considerada para definir a amostra é utilizar a fórmula do tamanho da amostra para uma estimativa por intervalo de uma média da população com base em Anderson, Sweeney e Williams (2002). Para esse cálculo é necessário determinar o intervalo de confiança, o erro amostral e desvio padrão da população. Para definir o tamanho da amostra desta pesquisa, foi considerado o intervalo de confiança de $99 \%$ com o valor de $Z$ crítico igual a 2,57 e um erro de 0, 226.

Anderson, Sweeney e Williams (2002) explicam que, quando o desvio padrão populacional não é conhecido, uma das alternativas é adotar o desvio padrão encontrado a partir de um estudo piloto feito com uma amostra preliminar. Visto isso, o desvio padrão amostral utilizado para o cálculo da amostra foi obtido a partir de um estudo realizado pela pesquisadora, anteriormente ao desenvolvimento desta pesquisa, na mesma população aqui estudada. Nesta ocasião 51 amostras foram utilizadas, no qual o valor do desvio padrão obtido foi igual a 1, 240809. Assim também se chegou a 200 amostras necessárias $(n=200)$, conforme fórmula abaixo.

$$
\left(\frac{z . \text { desvio padrão }}{\text { erro }}\right)^{2}=\text { tamanho da amostra } \rightarrow\left(\frac{2,575 \cdot 1,240809}{0,226}\right)^{2}=\mathbf{1 9 9 , 0 9}
$$

A amostragem foi de tipologia probabilística, em que cada elemento da população tem a mesma chance de ser incluída na amostra, permitindo uma melhor representação da população (Malhotra, 2006). A técnica utilizada foi a sistemática, na qual existiu um ponto de partida determinado para cada entrevistador. A partir desse ponto a primeira mesa era escolhida de forma aleatória e, na sequência, a cada duas mesas ocupadas, uma foi abordada. Quando os sujeitos estavam em grupos, apenas uma das pessoas foi selecionada para responder ao questionário, esta foi a primeira da direita, salvos os casos em que essa primeira pessoa era menor de 18 anos ou era a primeira vez que consumia.
Nesses casos, a próxima pessoa da direita respondeu ao questionário.

\section{ANÁLISE E DISCUSSÃO DOS DADOS}

Neste tópico são expostos os dados levantados junto aos clientes que consomem comida de rua da Praça de Jardim da Penha.

\subsection{Análise da Etapa Qualitativa}

Nesta etapa, procurou-se identificar quais eram os atributos considerados mais importantes pelos consumidores no momento da compra de comida de rua, para que fosse possível estruturar um questionário survey com os atributos 
inerentes ao consumo de comida de rua. Os dados gerados a partir dessas entrevistas foram estudados por meio de uma análise de conteúdo, na qual resultou uma lista de atributos e suas respectivas categorias.

Bardin (1996) explica que, ao realizar a análise de conteúdo, é necessário o desenvolvimento de três passos: pré-análise, exploração do material e tratamento dos resultados (inferência). Na pré-análise foi realizada a leitura e seleção dos materiais a serem avaliados, selecionados estudos que utilizaram escalas que continham atributos relacionados ao consumo de alimentos em diversos tipos de restaurantes, para explorálos, bem como os relatos das entrevistas. Assim, a análise de conteúdo foi formada por dois corpus: material obtido no levantamento feito a partir da literatura e o referente às respostas das entrevistas semiestruturadas, realizadas junto aos clientes que consomem comida de rua, gerando uma listagem dos atributos.

$\mathrm{Na}$ fase de exploração ocorreu a codificação, na qual os atributos que possuíam o mesmo significado foram agregados. Posteriormente, cada um desses grupos codificados foi nomeado de acordo com o seu significado. Para definir aqueles que seriam utilizados no estudo, considerouse a ordem de aparições, ou seja, os mais frequentes, bem como a sua adequação ao tema e objeto de estudo. Por fim, foram definidas as categorias. Para criar as categorias deste estudo, utilizou-se o critério semântico, ou seja, os temas que semanticamente estão ligados a uma categoria, definida pelo autor, ficam agrupados nela (Bardin, 1996).
No total foram dezoito (18) atributos divididos em cinco (5) categorias, conforme apresentado no quadro 04 (página. 15). Concluída a análise de conteúdo, foi estruturado o questionário survey, instrumento de coleta de dados utilizado na etapa quantitativa deste trabalho.

\subsection{Análise da Etapa Quantitativa}

O questionário do tipo survey foi utilizado para a obtenção dos dados na etapa quantitativa. Após sua aplicação, os dados foram devidamente preparados e alinhados em um formato apropriado para análise, conforme indicação de Malhotra (2006) e Hair et al., (2005). A seguir são apresentados os resultados obtidos.

\subsubsection{Perfil}

Buscou-se identificar quem são os clientes que consomem comida de rua na Praça de Jardim da Penha. Especificamente, foram levantadas informações referentes ao gênero, à frequência com que essas pessoas compram comida de rua na praça, à faixa etária, à região que residem e à renda do domicílio dos entrevistados.

Em relação ao gênero, obteve-se um maior quantitativo relativo ao feminino (59\%), conforme gráfico 01 . Quanto à variável faixa etária dos respondentes, foi possível verificar a maior composição (19\%) entre 24 e 29 anos, conforme o gráfico 02 . De acordo com esses dados é possível perceber que os jovens e os adultos com até 35 anos são os que têm maior representatividade no 
consumo de alimentos de rua, na Praça de Jardim da Penha.

Quando perguntado sobre a frequência de compra de comida de rua na praça, uma grande quantidade de entrevistados lasemanalmente (41,5\%). Assim, a partir desses resultados pode-se afirmar que a maioria dos entrevistados tem o hábito de comprar, regularmente, comida de rua na praça, conforme gráfico 03.

\section{Gráfico 01 - Gênero}

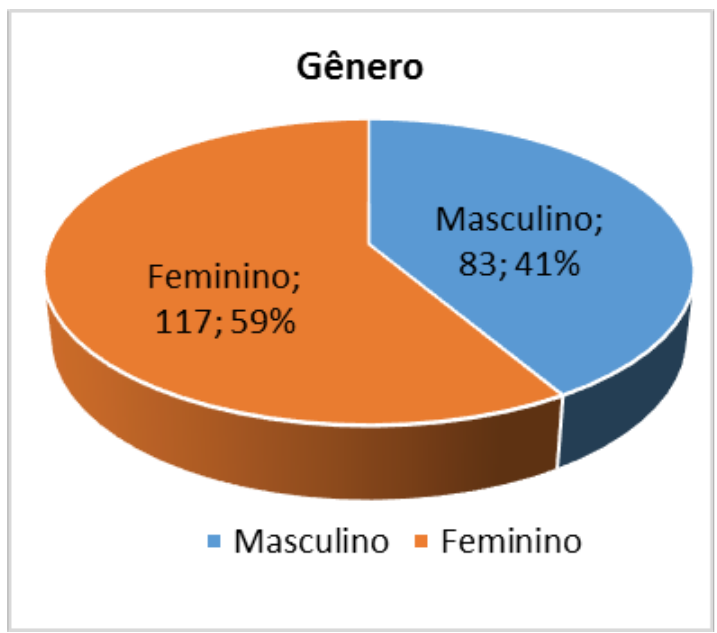

Fonte: Dados da pesquisa

\section{Gráfico 02 - Faixa Etária}

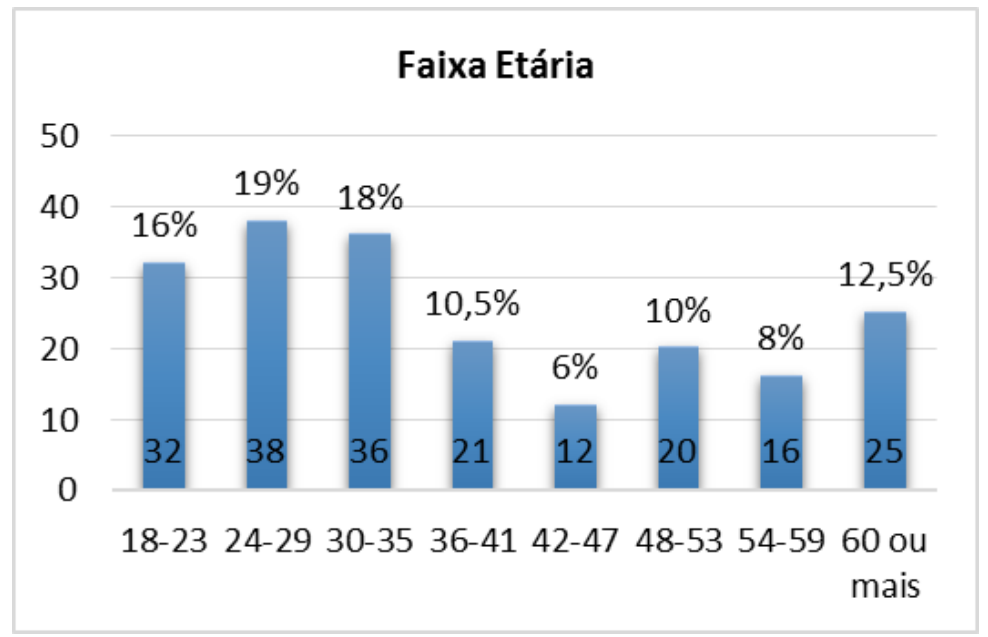

Fonte: Dados da pesquisa 
Gráfico 03 - Frequência de compra

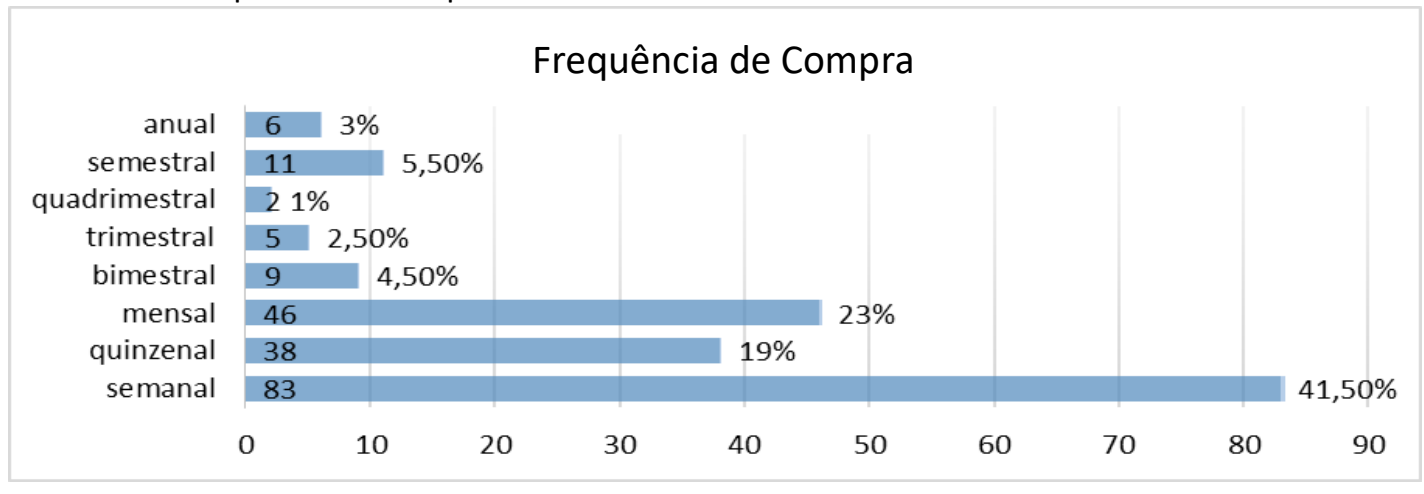

Fonte: Dados da pesquisa

Para identificar a classe social à qual pertencem os entrevistados, foi perguntada a renda do domicílio, ou seja, a renda somada de todas as pessoas que moram no domicílio. As faixas de renda utilizadas neste trabalho tiveram como base os critérios de classificação econômica da Abep (Associação brasileira de empresas de pesquisa), na qual os estratos do Critério Brasil representam a renda média domiciliar mensal para os estratos econômicos. Essa estratificação não é baseada no valor do salário mínimo vigente. A partir de janeiro de 2015, as estratificações de rendas adotadas são as descritas no gráfico 04. É importante ressaltar que, com o objetivo de facilitar a aplicação do questionário e simplificar a leitura dos números, os dígitos que representam os centavos foram arredondados.

Gráfico 04 - Renda do domicílio

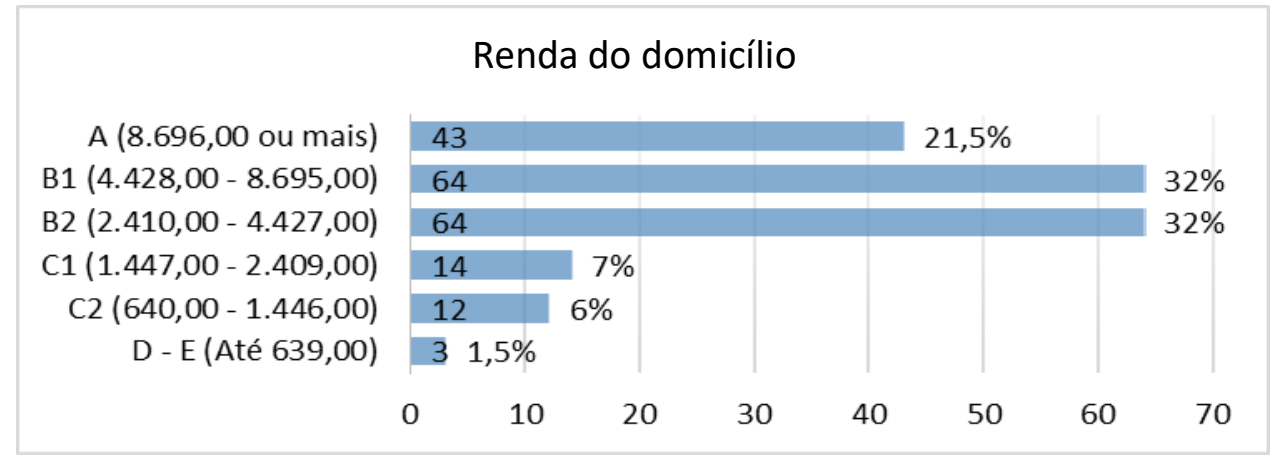

Fonte: Dados da pesquisa

Ao analisar o gráfico 04, é possível notar que a maioria das pessoas que participaram do estudo representa os estratos econômicos B1 (32\%) e B2 (32\%). Assim, pode-se afirmar que os consumidores da Praça de Jardim da Penha são, em sua maioria, pessoas de classe média a classe média alta. Esse resultado não confirma o que supõe o relatório da FAO (2011), o qual afirma que a maior parte das pessoas que consomem comida de rua tem baixo poder aquisitivo. 


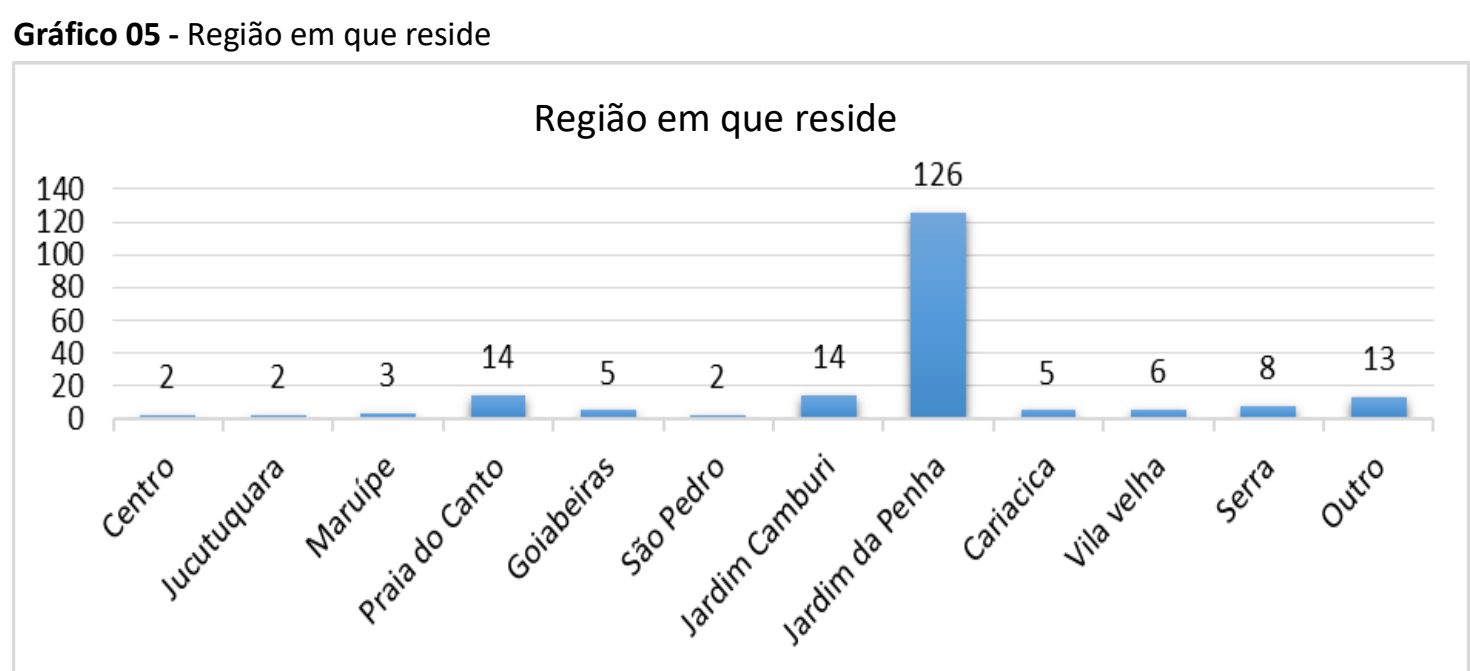

Fonte: Dados da pesquisa

Em relação ao local de residência, 126 pessoas (63\%) afirmaram que moram na região de Jardim da Penha, conforme gráfico 05. A partir desse percentual fica evidente que a praça é frequentada, principalmente, pelas pessoas do próprio bairro.

\subsubsection{Importância dos Atributos na Decisão de Compra}

Na segunda parte do questionário, os clientes foram interrogados sobre a importância dos atributos para a sua decisão de compra de alimentos de rua, visto que no processo que antecede a compra, conforme expressam Blackwell, Miniard e Engel (2005), os consumidores avaliam as diferentes possibilidades de que dispõem para tomar sua decisão de compra, de acordo com aquela que melhor se enquadra nos parâmetros que são exigidos por eles.

Entretanto, por se tratar de um estudo exploratório, foi desenvolvida uma escala para mensurar a importância desses atributos, o que tornou necessário o desenvolvimento da Análise Fatorial Exploratória. Segundo Brown (2006) a AFE é geralmente conduzida quando o pesquisador não possui uma teoria prévia subjacente ou evidências empíricas suficientes que explicitem como os itens de determinado instrumento devem ser agrupados e avaliados.

\subsubsection{Análise Fatorial Exploratória (AFE) da Importância dos Atributos}

Considerando-se que os atributos identificados na fase qualitativa formaram uma escala de 18 itens, tornou-se relevante verificar a distribuição desses dados. Para isso, foi utilizado o procedimento estatístico de Análise Fatorial Exploratória (AFE). A análise fatorial auxilia nas evidências relativas à validade de questionários, comumente utilizados em pesquisas (Hair et al., 2005).

A AFE foi realizada separadamente em cada uma das dimensões (categorias) com a finalidade de auxiliar na avaliação da distribuição dos atributos nas dimensões, assim refletiu-se sobre essa distribuição e organização da escala, a partir da teoria que cerne os atributos e AFE. 
A técnica analítica fatorial utilizada foi a perspectiva exploratória, pois é "[...] útil na busca da estrutura de um conjunto de variáveis ou como um método de redução de dados [...]" (Hair et al., 2005, p. 92). Normalmente a análise fatorial exploratória (AFE) é utilizada em pesquisas iniciais com a finalidade de explorar os dados.

Para o desenvolvimento desta análise foi realizada a rotação fatorial oblíqua, na qual se identifica o grau em que cada fator está correlacionado (Hair et al., 2005). A rotação fatorial é realizada com o objetivo de ajustar os eixos fatoriais em busca de soluções simples e mais significativas, melhorando a interpretação e reduzindo ambiguidades. (Hair et al., 2005). A análise fatorial foi realizada utilizando o Software SPSS. A seguir são apresentados os critérios e resultados da AFE.

\subsubsection{Resultados da Análise Fatorial Exploratória}

Inicialmente foram realizados os testes KMO e Bartlett. Esses testes verificam se a análise fatorial é adequada. O teste de Kaiser-Meyer-Olklin (KMO) varia entre 0 e 1. Quanto mais perto de 1 melhor, sendo que valores entre 0,5 e 1 são aceitáveis (Hair et al., 2005). Valores abaixo de 0,5 indicam inadequação do método (Hair et al., 2005). Para o teste de esfericidade de Bartlett (BTS) os valores adequados são os menores que $0,05(p<0,05)$. Conforme quadro 01 , todos os valores estão dentro do limite indicado.

Para determinar o número de fatores a serem extraídos, utilizou-se a regra da raiz latente, na qual os autovalores (eigenvalue) maiores que 01 devem ser retidos, sempre tentando atingir o mínimo recomendado de $60 \%$ de variância acumulada, indicados por Hair et al. (2005). Ao realizar esse procedimento, os atributos da dimensão "alimentos" se distribuíram em três componentes para uma maior variância acumulada. Entretanto a variável "alimento saudável" formaria um único constructo.

Esse dado deu margem a uma reflexão teórica sobre esta variável. Ao contrário dos estudos de Liu e Jang (2009); Harrington, Ottenbacher e Way (2011) e Castelo Branco (2000) que evidenciam apenas a variável alimento saudável, outros autores como Steptoe, Pollard e Wardle (1995) e Yuksel e Yukesel (2002) dão evidência de que a variável "alimento saudável" pode ser composta por outros fatores, considerando, por exemplo, o teor calórico dos alimentos e a quantidade de vitaminas, nutrientes, proteínas e gordura. Assim, observa-se que esta variável não está completa da forma a qual foi mensurada, por isto resolveu-se retirar essa variável da escala. Foram, então formados dois componentes e renomeados, conforme quadro 01. 
Quadro 01 - Dados a partir da Análise Fatorial Exploratória

\begin{tabular}{|c|c|c|c|c|}
\hline Dimensão & $\begin{array}{l}\text { KMO e } \\
\text { Bartlett }\end{array}$ & $\begin{array}{l}\text { Variância } \\
\text { acumulada }\end{array}$ & Descrição dos componentes & $\begin{array}{l}\text { Variável } \\
\text { excluída }\end{array}$ \\
\hline \multirow[t]{2}{*}{ Alimentos } & $\begin{array}{l}753 \\
, 000\end{array}$ & 56,055 & $\begin{array}{l}\text { Componente 1: aspecto, sabor, cheiro e tempera- } \\
\text { tura. Esse componente foi nomeado de Caracterís- } \\
\text { ticas organolépticas dos alimentos. }\end{array}$ & $\begin{array}{l}\text { Alimento } \\
\text { saudável }\end{array}$ \\
\hline & & & $\begin{array}{l}\text { Componente 2: Variedade e Higiene. Esse compo- } \\
\text { nente permaneceu com a nomenclatura de Ali- } \\
\text { mentos, entendendo que são as características } \\
\text { não organolépticas dos alimentos. }\end{array}$ & \\
\hline Ambiente & $\begin{array}{l}742 \\
000\end{array}$ & 55,036 & $\begin{array}{l}\text { Estrutura, Ambiente Familiar, Ambiente Aberto, } \\
\text { Segurança }\end{array}$ & ---- \\
\hline Serviço & $\begin{array}{l}655 \\
, 000\end{array}$ & 60,282 & $\begin{array}{l}\text { Rapidez no atendimento, Bom Atendimento, Apa- } \\
\text { rência e higiene dos funcionários }\end{array}$ & ---------- \\
\hline Conveniência & , 500 & 63,203 & Localização, Praticidade & ----------- \\
\hline Preço & , 500 & 69,772 & Facilidade de pagamento e valor & - \\
\hline
\end{tabular}

Fonte: Dados da pesquisa originados do SPSS

Após a AFE, as demais dimensões permaneceram com a mesma estrutura da escala utilizada originalmente, conforme dados do quadro 02.

As comunalidades representam a quantia total de variância que uma variável original compartilha com todas as outras incluídas na análise. Hair et al. (2005) sugerem que os níveis aceitáveis de comunalidade devem ser iguais ou superiores a 0,5. Valores abaixo disso devem ser avaliados e cabe ao pesquisador a decisão de manter ou não a variável (Hair et al., 2005). É possível verificar que a variável "cheiro" e "segurança" apresentam comunalidades abaixo do valor crítico $(0,371)$, no entanto optou-se por conservar esta variável devido ao suporte teórico.

Quadro 02 - Comunalidades e Cargas Fatoriais

\begin{tabular}{|c|c|c|c|c|}
\hline Dimensão & Atributos & Inicial & Extração & Cargas \\
\hline $\begin{array}{l}\text { Características orga- } \\
\text { nolépticas }\end{array}$ & $\begin{array}{l}\text { Temperatura } \\
\text { Cheiro } \\
\text { Aspecto } \\
\text { Sabor }\end{array}$ & $\begin{array}{l}1,000 \\
1,000 \\
1,000 \\
1,000\end{array}$ & $\begin{array}{l}556 \\
, 371 \\
, 594 \\
, 548\end{array}$ & $\begin{array}{l}656 \\
, 601 \\
, 622 \\
, 737\end{array}$ \\
\hline Alimentos & $\begin{array}{l}\text { Higiene } \\
\text { Variedade }\end{array}$ & $\begin{array}{l}1,000 \\
1,000\end{array}$ & $\begin{array}{l}605 \\
, 690 \\
\end{array}$ & $\begin{array}{l}-, 497 \\
, 649 \\
\end{array}$ \\
\hline Ambiente & $\begin{array}{l}\text { Estrutura } \\
\text { Ambiente Familiar } \\
\text { Ambiente Aberto } \\
\text { Segurança }\end{array}$ & $\begin{array}{l}1,000 \\
1,000 \\
1,000 \\
1,000\end{array}$ & $\begin{array}{l}, 571 \\
, 666 \\
, 540 \\
, 425 \\
\end{array}$ & $\begin{array}{l}756 \\
, 816 \\
, 735 \\
, 652 \\
\end{array}$ \\
\hline Serviço & $\begin{array}{l}\text { Rapidez no atendimento } \\
\text { Bom Atendimento } \\
\text { Aparência e higiene dos funcionários }\end{array}$ & $\begin{array}{l}1,000 \\
1,000 \\
1,000\end{array}$ & $\begin{array}{l}, 593 \\
, 652 \\
, 563 \\
\end{array}$ & $\begin{array}{l}, 770 \\
, 808 \\
, 750 \\
\end{array}$ \\
\hline Conveniência & $\begin{array}{l}\text { Localização } \\
\text { Praticidade }\end{array}$ & $\begin{array}{l}1,000 \\
1,000\end{array}$ & $\begin{array}{l}632 \\
, 632 \\
\end{array}$ & $\begin{array}{l}, 795 \\
, 795 \\
\end{array}$ \\
\hline Preço & $\begin{array}{l}\text { Valor } \\
\text { Facilidade de pagamento }\end{array}$ & $\begin{array}{l}1,000 \\
1,000\end{array}$ & $\begin{array}{l}698 \\
, 698\end{array}$ & $\begin{array}{l}835 \\
, 835\end{array}$ \\
\hline
\end{tabular}

Fonte: Dados da pesquisa originados do SPSS 
No quadro 02 , observam-se ainda os valores das cargas fatoriais dos componentes. Hair et al. (2005) explicam que a carga fatorial é a correlação entre a variável e o fator. Representa o limite aceitável da contribuição da variável na criação do fator com o objetivo de evitar o problema da indeterminação da relação entre variáveis e fatores. Para significância estatística de uma amostra de 200, como é o caso deste estudo, as cargas devem ser iguais ou maiores que 0,4 (Hair et al., 2005).

Para testar a confiabilidade, utilizouse o cálculo do coeficiente Alpha de Cronbach, que se constitui em um dos procedimentos mais adotados para avaliar a confiabilidade de uma escala (Malhotra, 2001). Segundo Hair et al. (2005), o valor do Alfa de Cronbach deve variar entre 0,6 a 0,9 para serem aceitos.

O valor do alfa de Cronbach é influenciado tanto pelo valor das correlações dos itens, quanto pelo número de itens avaliados. Por isso, fatores com poucos itens tendem a apresentar alfas de Cronbach menores (Cortina, 1993). Nos constructos "conveniência" e "preço", é possível observar baixos valores para o Alfa de Cronbach (vide quadro 03), ficando abaixo do indicado pela literatura.

Quadro 03- Estatísticas de confiabilidade

\begin{tabular}{cccccc}
\hline Dimensão & Alimentos & Ambiente & Serviço & $\begin{array}{c}\text { Conveniên- } \\
\text { cia }\end{array}$ & Preço \\
\hline Alfa de Cronbach &, 676 &, 721 &, 660 &, 417 &, 554 \\
\hline
\end{tabular}

Fonte: Dados da pesquisa originados do SPSS

A partir do desenvolvimento da análise fatorial exploratória, foi possível inferir algumas modificações em relação aos atributos e constructos inicialmente utilizados nesta pesquisa, de modo que a escala original sofreu ajustes para melhor confiabilidade e validade ao questionário, conforme observado no quadro 04.

Quadro 04 - Resultado da análise fatorial exploratória

\begin{tabular}{|l|l|l|l|}
\hline \multicolumn{1}{|c|}{ Escala conceitual (antes da análise fatorial) } & \multicolumn{1}{|c|}{$\begin{array}{c}\text { Avaliação empírica da escala (após a análise fato- } \\
\text { rial) }\end{array}$} \\
\hline Componente & \multicolumn{1}{|c|}{ Variável } & \multicolumn{1}{c|}{ Componente } & \multicolumn{1}{c|}{ Variável } \\
\hline \multirow{2}{*}{ 1.Alimentos } & $\begin{array}{l}\text { B1.Alimento saudável } \\
\text { B2. Variedade } \\
\text { B3. Aspecto } \\
\text { B4. Sabor } \\
\text { B5. Cheiro } \\
\text { B6. Temperatura } \\
\text { B7. Higiene }\end{array}$ & $\begin{array}{l}\text { 1.Características orga- } \\
\text { nolépticas }\end{array}$ & $\begin{array}{l}\text { B1.Alimento saudável } \\
\text { B2. Aspecto } \\
\text { B3. Sabor } \\
\text { B4. Cheiro } \\
\text { B5. Temperatura }\end{array}$ \\
\cline { 2 - 4 } & $\begin{array}{l}\text { B8. Estrutura Física } \\
\text { B9. Ambiente Familiar } \\
\text { B10. Ambiente Aberto } \\
\text { B11. Segurança }\end{array}$ & 2.Alimentos & $\begin{array}{l}\text { B6. Variedade } \\
\text { B7. Higiene }\end{array}$ \\
\hline 3.Serviço & $\begin{array}{l}\text { B12. Rapidez no Atendimento } \\
\text { B13. Bom atendimento } \\
\text { B14. Aparência e higiene dos } \\
\text { funcionários }\end{array}$ & 4.Serviço & $\begin{array}{l}\text { B8. Estrutura Física } \\
\text { B9. Ambiente Familiar } \\
\text { B10. Ambiente Aberto } \\
\text { B11. Segurança }\end{array}$ \\
\hline 4.Conveniência & $\begin{array}{l}\text { B15. Localização } \\
\text { B16. Praticidade }\end{array}$ & $\begin{array}{l}\text { B12. Rapidez no Atendimento } \\
\text { B13. Bom atendimento } \\
\text { B14. Aparência e higiene dos } \\
\text { funcionários }\end{array}$ \\
\hline 5.Preço & $\begin{array}{l}\text { B17. Valor do alimento } \\
\text { B18. Facilidade de pagamento }\end{array}$ & 6.Preço & $\begin{array}{l}\text { B15. Localização } \\
\text { B16. Praticidade }\end{array}$ \\
\hline
\end{tabular}

Fonte: Elaborado pelos autores 


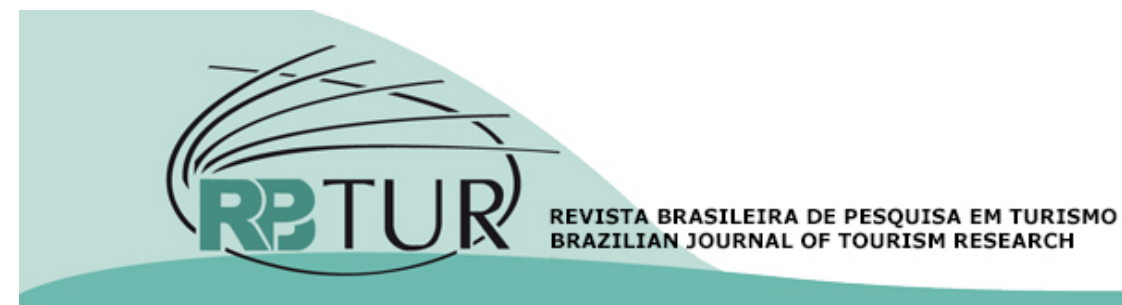

Após a análise fatorial, obtiveram-se as alterações na escala evidenciadas no quadro 5. Essa nova estrutura foi a considerada para as análises da importância dos atributos apresentadas no próximo tópico.

\subsubsection{Análise da importância dos Atribu- tos}

A hipótese norteadora deste estudo fundamenta-se na teoria de Alpert (1971), a qual afirma que os atributos podem apresentar diferentes graus de importância. Para responder o problema dessa pesquisa, a hipótese fundamentou-se em identificar se há diferença no grau de importância atribuído pelos clientes aos atributos.

Assim, foram desenvolvidas hipóteses para testar igualdades e diferenças entre as médias, de modo a comprovar ou refutar a teoria de Alpert (1971). Sendo a primeira hipótese a seguinte:
Ha: Não há diferença no grau de importância, atribuída pelos clientes, aos atributos.

Para este teste, considerou-se o intervalo de confiança de 95\%, com o nível de significância $(\alpha)$ de 0,05 . Segundo Levine et al. (2012), se o p-valor ficar abaixo do nível de significância previamente estabelecido $(\alpha=0,05)$ HO é não confirmada, o que evidencia que pelo menos uma das médias é diferente das demais. Quando o p-valor ficar acima do nível de significância previamente estabelecido $(\alpha=0,05) \mathrm{HO}$ não refutada.

Para testar a hipótese (Ha), foi utilizada a ferramenta Excel e realizados os testes para a análise de variância (ANOVA). A variância mede quanto é a média de variação em torno da média aritmética dos atributos, de modo a verificar se há diferença estatística entre essas médias (Levine et al., 2012). Os resultados obtidos nesse teste são apresentados na tabela 01 .

Tabela 01 - ANOVA da Importância

\begin{tabular}{|c|c|c|c|c|c|c|}
\hline Fonte da variação & SQ & GI & MQ & $\mathbf{F}$ & Valor-P & F crítico \\
\hline Entre grupos & 36,5716666 & 5 & 7,314333333 & 11,7025 & $4,609 \mathrm{E}-11$ & 2,22159 \\
\hline Dentro dos grupos & 746,2775 & 1194 & 0,625023032 & & & \\
\hline Total & 782,849166 & 1199 & & & & \\
\hline
\end{tabular}

Fonte: Dados da pesquisa

Ao analisar o p-valor $(4,609 \mathrm{E}-11)$ pode-se concluir que este valor é menor que 0,05 . Em números comuns essa notação científica equivale a aproximadamente 0 (zero). Isso indica que a HO é rejeitada, ou seja, pelo menos uma das médias é diferente das demais. Essa informação supõe que pelo menos um dos constructos exerce influência diferente dos demais na decisão de compra, há então diferentes graus de importância, atribuídos pelos clientes aos constructos. Dessa forma, confirma-se a teoria de Alpert 
(1971) quanto à existência de diferença no grau de importância atribuído pelos clientes aos atributos.

\subsubsection{Classificação dos Atributos}

É necessário ainda saber qual ou quais constructos têm médias diferentes dos demais e colocá-los em ordem decrescente de importância para, se possível, classificálos em determinantes, importantes e salientes. Apenas constructos que apresentaram médias estatisticamente iguais foram classificados da mesma forma.

Visando identificar qual constructo apresenta média distinta dos demais, foram realizados novos testes de hipóteses envolvendo dois constructos a cada teste. Para esse novo teste de hipóteses utilizou-se o teste $t$ para diferença entre duas médias pressupondo variâncias diferentes. Método utilizado para avaliar as diferenças estatísticas entre duas médias aritméticas (Levine et al., 2012). O teste foi realizado com auxílio da ferramenta Excel. As hipóteses para este teste foram as apresentadas no quadro 05 , bem como o valor-p obtido em cada um desses testes e os resultados das hipóteses.

Quadro 05 - Hipóteses testadas

\begin{tabular}{|c|c|c|}
\hline Hipótese: $\mathrm{HO}(\mu 1=\mu 2)$ & Valor-p & Situação \\
\hline $\begin{array}{l}\text { Haa: Não há uma diferença do grau de importância, atribuída pelos cli- } \\
\text { entes, entre os constructos características organolépticas e alimentos. }\end{array}$ & 0,87149 & $\begin{array}{l}\text { H0 não refutada, mé- } \\
\text { dias não diferentes }\end{array}$ \\
\hline $\begin{array}{l}\text { Hab: Não há uma diferença do grau de importância, atribuída pelos cli- } \\
\text { entes, entre os constructos características organolépticas e ambiente. }\end{array}$ & 0,05205 & $\begin{array}{l}\text { HO não refutada, mé- } \\
\text { dia não diferentes }\end{array}$ \\
\hline $\begin{array}{l}\text { Hac: Não há uma diferença do grau de importância, atribuída pelos cli- } \\
\text { entes, entre os constructos características organolépticas e serviços. }\end{array}$ & 0,01180 & $\begin{array}{l}\text { HO não confirmada, } \\
\text { médias diferentes }\end{array}$ \\
\hline $\begin{array}{l}\text { Had: Não há uma diferença do grau de importância, atribuída pelos cli- } \\
\text { entes, entre os constructos características organolépticas e conveniên- } \\
\text { cia. }\end{array}$ & 0,00106 & $\begin{array}{l}\text { HO não confirmada, } \\
\text { médias diferentes }\end{array}$ \\
\hline $\begin{array}{l}\text { Hae: Não há uma diferença do grau de importância, atribuída pelos cli- } \\
\text { entes, entre os constructos características organolépticas e preço. }\end{array}$ & $1,28 \mathrm{E}-05$ & $\begin{array}{l}\text { HO não confirmada, } \\
\text { médias diferentes }\end{array}$ \\
\hline $\begin{array}{l}\text { Haf: Não há uma diferença do grau de importância, atribuída pelos cli- } \\
\text { entes, entre os constructos alimentos e ambiente. }\end{array}$ & 0,08847 & $\begin{array}{l}\text { HO não refutada, mé- } \\
\text { dias não diferentes }\end{array}$ \\
\hline $\begin{array}{l}\text { Hag: Não há uma diferença do grau de importância, atribuída pelos cli- } \\
\text { entes, entre os constructos alimentos e serviço. }\end{array}$ & 0,01094 & $\begin{array}{l}\text { HO não confirmada, } \\
\text { médias diferentes }\end{array}$ \\
\hline $\begin{array}{l}\text { Hah: Não há uma diferença do grau de importância, atribuída pelos cli- } \\
\text { entes, entre os constructos alimentos e conveniência. }\end{array}$ & 0,00230 & $\begin{array}{l}\text { HO não confirmada, } \\
\text { médias diferentes }\end{array}$ \\
\hline $\begin{array}{l}\text { Hai: Não há uma diferença do grau de importância, atribuída pelos cli- } \\
\text { entes, entre os constructos alimentos e preço. }\end{array}$ & $4,14 \mathrm{E}-05$ & $\begin{array}{l}\text { HO não confirmada, } \\
\text { médias diferentes }\end{array}$ \\
\hline $\begin{array}{l}\text { Haj: Não há uma diferença do grau de importância, atribuída pelos cli- } \\
\text { entes, entre os constructos ambiente e serviço. }\end{array}$ & $7,35 \mathrm{E}-05$ & $\begin{array}{l}\text { HO não confirmada, } \\
\text { médias diferentes }\end{array}$ \\
\hline $\begin{array}{l}\text { Hak: Não há uma diferença do grau de importância, atribuída pelos cli- } \\
\text { entes, entre os constructos ambiente e conveniência. }\end{array}$ & 0,10985 & $\begin{array}{l}\text { HO não refutada, mé- } \\
\text { dias não diferentes }\end{array}$ \\
\hline $\begin{array}{l}\text { Hal: Não há uma diferença do grau de importância, atribuída pelos cli- } \\
\text { entes, entre os constructos ambiente e preço. }\end{array}$ & 0,0092 & $\begin{array}{l}\text { HO não confirmada, } \\
\text { médias diferentes }\end{array}$ \\
\hline $\begin{array}{l}\text { Ham: Não há uma diferença do grau de importância, atribuída pelos } \\
\text { clientes, entre os constructos serviço e conveniência. }\end{array}$ & $1,05 E-06$ & $\begin{array}{l}\text { HO não confirmada, } \\
\text { médias diferentes }\end{array}$ \\
\hline $\begin{array}{l}\text { Han: Não há uma diferença do grau de importância, atribuída pelos cli- } \\
\text { entes, entre os constructos serviço e preço. }\end{array}$ & 4,45E-09 & $\begin{array}{l}\text { HO não confirmada, } \\
\text { médias diferentes }\end{array}$ \\
\hline $\begin{array}{l}\text { Hao: Não há uma diferença do grau de importância, atribuída pelos cli- } \\
\text { entes, entre os constructos conveniência e preço. }\end{array}$ & 0,39113 & $\begin{array}{l}\text { HO não refutada, mé- } \\
\text { dias não diferentes }\end{array}$ \\
\hline
\end{tabular}

Fonte: Elaborado pelos autores 


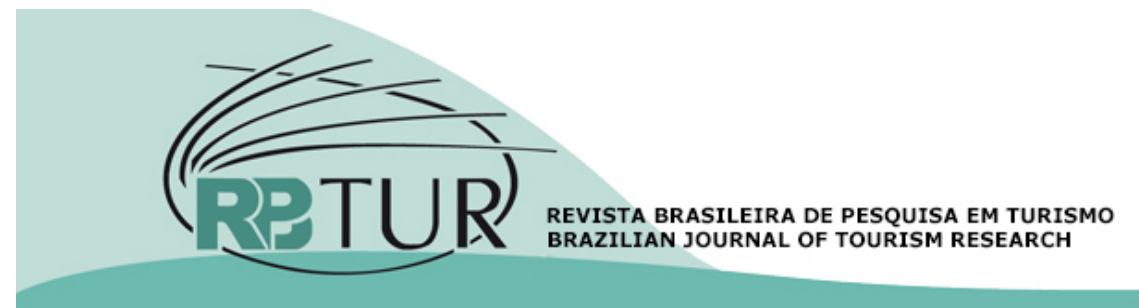

Para a classificação quanto ao grau de importância, aqueles constructos com médias não diferentes entre si foram considerados pertencentes à mesma classificação. Assim, seguindo a hierarquia, para fins de classificação, o constructo "conveniência" foi considerado juntamente com o "preço", mas separado de "ambiente", pois "preço" e "ambiente" apresentaram médias não iguais (vide quadro 05), o que demonstra a existência de uma zona cinzenta representada na figura 01 . Isso evidencia que pode haver outras possíveis formas de classificações. Como neste trabalho buscaram-se as disposições segundo a teoria de Alpert (1971), foram limitadas, no máximo, três classificações quanto à importância dos constructos. Obteve-se a classificação evidenciada na figura 01 quanto ao grau de importância dos constructos.

Figura 1 - Classificação da importância dos constructos evidenciando a zona cinzenta

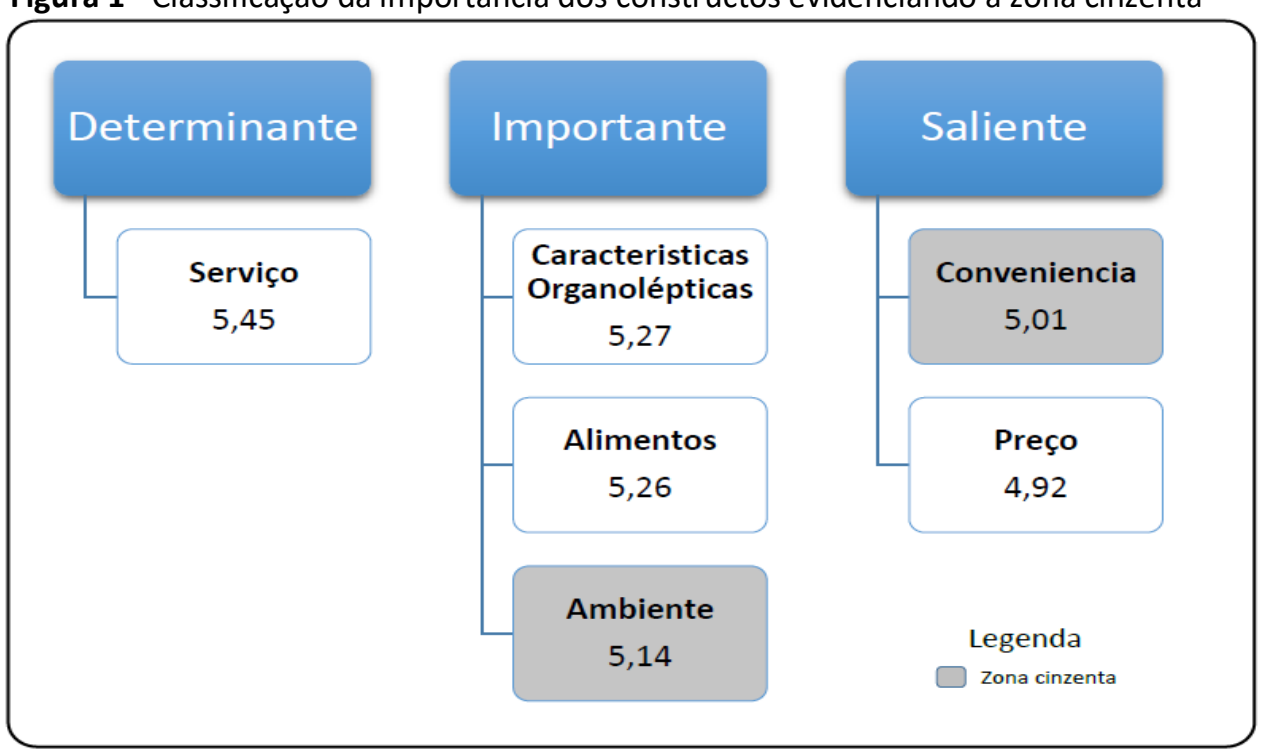

Fonte: Elaborado pelos autores

Respondendo ao problema desta pesquisa, pode-se observar que o constructo determinante é o serviço. Este constructo é formado pelos atributos: rapidez no atendimento, bom atendimento, aparência e higiene dos funcionários. Os constructos importantes são: características organolépticas, formado por: aspecto, sabor, cheiro, temperatura. Alimentos, formado por variedade e higiene. E ambiente, formado por: estrutura física, ambiente familiar, ambiente aberto e segurança. No constructo saliente estão a conveniência, constructo formado por: praticidade e localização. E preço, formado por valor e facilidade de pagamento.

Esses resultados vão ao encontro dos revelados por Mhlanga, Hattingh e Moolman 
(2014), nos quais esses autores evidenciaram que o nível do serviço é o principal fator considerado pelos clientes no contexto de restaurantes. Ainda de acordo com o estudo desses autores, as características organolépticas, essenciais para oferecer uma boa comida, também foram evidenciadas como importantes e identificadas logo após o serviço.

Relacionado aos serviços, Sanches e Salay (2011) revelam que a higiene dos funcionários é o fator mais importante quando se trata de escolher um restaurante para realizar as refeições fora do domicílio.

O estudo de Namkung e Jang (2007) demonstrou que o aspecto, sabor e temperatura (características organolépticas) foram as mais significativas para obter a satisfação do cliente em restaurantes. De forma similar Liu e Jang (2009) revelaram que - sabor dos alimentos é essencial para influenciar nas decisões de compra. O serviço oferecido apareceu logo em seguida. No estudo de Park (2004) o sabor dos alimentos também foi obtido como o mais importante, seguido da higiene e serviço.

Soriano (2002) obteve resultados semelhantes, nos quais a variedade e apresentação do alimento foram a razão mais importante na influência de decisões dos clientes para retornar a um restaurante para outra refeição. O serviço foi o segundo fator mais importante.

Yuksel e Yuksel (2002) revelaram que, apesar de importante, o ambiente aparece como último fator relevante na influência na seleção e avaliação de restaurantes. De forma similar, Soriano (2002) obteve o ambiente como último fator considerado na influência de decisões dos clientes para retornar a um restaurante.

Harrington, Ottenbacher e Way (2011) evidenciaram que o preço e a distância (localização), apesar de fatores importantes não estão entre os primeiros na hierarquia de importância. Os resultados de Park (2004) e de Sanches e Salay (2011) também evidenciam este fato.

0 fator que se destaca por ser classificado de diferentes formas é o preço. Em alguns estudos, como o de Abdullah, Abdurahman e Hamali (2013) e Ehsan (2012), o preço foi considerado como a dimensão mais importante de preferência do cliente no setor de alimentos para selecionar restaurantes. Já nos estudos de Siebeneichler et al. (2007) e Souki (2010), o preço e facilidade de pagamento aparecem como o último fator na ordem de importância. Assim, apesar de importante para a decisão de compra, existem outros fatores que oferecidos, como alta performance, tornam o consumidor menos sensível ao preço.

Os resultados encontrados neste estudo identificaram que o preço é uma variável importante para a decisão de compra, entretanto não representa o grau mais elevado de importância. Dessa forma, corrobora-se com os resultados de Pelissari et al. (2011), nos quais os autores afirmam que, embora o preço seja uma variável influente na decisão de compra, não caracteriza necessariamente um determinante para os clientes, mas é importante destacar que atua diretamente como um fator de competitividade. De forma similar, Reis (2004) afirma que diante de um mercado em que os produtos e serviços estão 
cada vez mais parecidos, os clientes dão importância a outros fatores além do preço.

Este estudo confirma a teoria de Griffin (1998), no qual este assume que os consumidores estão se tornando mais interessados no atendimento e na forma como são tratados ao adquirirem alguma coisa, representando o fator serviço deste trabalho. Assim, esse interesse relacionado ao atendimento supera, inclusive, a questão do preço e do produto (Griffin, 1998).

\section{CONSIDERAÇÕES FINAIS}

Este trabalho teve como escopo estudar um campo ainda pouco explorado, buscando entender e aprofundar lacunas existentes no que diz respeito ao consumo de comida de rua. $\mathrm{O}$ objetivo geral desta pesquisa centrou-se em identificar quais atributos são determinantes para os consumidores na tomada de decisão de compra em estabelecimentos que comercializam comida de rua, a partir do levantamento de dados e análise em uma Praça localizada na cidade de Vitória/ES.

As categorias utilizadas foram: alimentos, ambiente, serviço, conveniência e preço. Assim, existe uma colaboração deste trabalho em relação à criação de uma escala para o desenvolvimento de pesquisas, no setor de comida de rua, no que tange à mensuração da importância e satisfação de atributos e constructos.

A partir dos dados obtidos na fase quantitativa, foi possível identificar o perfil dos consumidores de comida de rua. A maioria dos consumidores pertence ao gênero feminino (59\%). A maior frequência de compra nesses estabelecimentos ocorre semanal (41,50\%) e mensalmente (23\%), caracterizando a existência regular de compras de comida de rua. As faixas etárias que mais se destacam são: 24 a 29 anos (19\%) e 30 a 35 anos (18\%), seguida dos idosos, 60 anos ou mais, que representam (12,5\%). Destacando o hábito de consumo nesses lugares de um público jovem, com faixa entre 24 a 35 anos, o qual representa o maior número de pessoas que consome semanalmente na praça. Trata-se de um público cuja maioria representa os estratos econômicos A e B. A maior parte do público frequentador, $63 \%$, reside no próprio bairro, Jardim da Penha.

Esses resultados refletem o perfil da população deste bairro. Trata-se de uma população jovem. É um bairro localizado em frente ao Campus da Universidade Federal do Espírito Santo (UFES), o que permite que um grande número de pessoas passe a residir no bairro, principalmente jovens estudantes.

Foi possível testar e confirmar a hipótese baseada na teoria de Alpert (1971), na qual se afirmou: há diferença no grau de importância, atribuído pelos clientes, aos atributos. A partir dos testes realizados, a hipótese foi confirmada, respondendo ao problema da pesquisa. Pode-se afirmar que existem atributos que exercem mais influência que outros na decisão de compra e classificar esses atributos quanto ao seu grau de importância. Foi identificado como o constructo determinante o "serviço". Este constructo tem como atributos: rapidez no atendimento, bom atendimento, aparência e higiene dos funcionários. São a esses atributos que os gestores devem voltar sua atenção, de forma a melhorá-los continuamente. 
De forma complementar, atendendo aos demais objetivos da pesquisa, tem-se como constructos importantes: "características organolépticas" , com os atributos: aspecto, sabor, cheiro e temperatura ; "alimentos", formado por variedade e higiene; e "ambiente", formado por estrutura física, ambiente familiar, ambiente aberto e segurança. No constructo saliente ainda temos a "conveniência", constructo formado por praticidade e localização; e "preço", formado por valor e facilidade de pagamento.

Assim, ao hierarquizar os atributos identificou-se que o "serviço" no topo da hierarquia, ao representar um grau de importância de 5,45 (em uma escala de no máximo 6). Em seguida aparecem "características organolépticas" $(5,27)$, "alimentos" $(5,26)$, "ambiente" $(5,14)$, "conveniência $(5,01)$ e "preço" (4,92).

Conclui-se que a atenção dos gestores desses empreendimentos deve se voltar para os atributos relacionados ao serviço. Muller e Woods (1994) afirmam que os gestores devem gastar recursos consideráveis nos atributos identificados como aqueles que irão satisfazer o maior número de clientes potenciais.

Como limitação, tem-se que esses resultados não representam a totalidade da realidade geral das praças brasileiras, são resultados restritos ao objeto estudado. Para pesquisas futuras sugere-se a ampliação deste estudo em outros locais de comida de rua, a fim de suprir as lacunas existentes teoricamente sobre o assunto, bem como comparar seus resultados de modo a verificar possíveis generalizações.

\section{REFERÊNCIAS}

Abdullah, F., Abdurahman, A. Z. A., \& Hamali, J. (2013). The dimensions of customer preference in the foodservice industry. Business: Theory and Practice/Verslas: Teorija ir Praktika, 14(1), 64-73.

Alpert, M. I. (1971). Identification of determinant attributes: a comparison of methods. Journal of Marketing Research, 184-191.

Anderson, D. R.; Sweeney, D. J.; Williams, T. A. (2002) Estatística Aplicada à Administração e Economia. Ed. Pioneira.

ABRASEL (2014). Gastos com alimentação fora de casa crescem em Itapetininga, SP. Recuperado em 15 de mar, 2015, de http://www.sp.abrasel.com.br/noticias/1663-06062014-gastos-comalimentacao-fora-de-casa-crescem-em-itapetininga-sp.

ABIA (2013) . Indústria brasileira da alimentação: desafios e oportunidades. Recuperado em 06 de jan, 2013, de http://www.abia.org.br/vst/publicacoes.html.

Bardin, L. (1977). Análise de Conteúdo. Lisboa: Edições 70.

Bezerra, I. N., Curioni, C., \& Sichieri, R. (2012). Association between eating out of home and body weight. Nutrition reviews, 70(2), 65-79.

Bezerra, I. N., \& Sichieri, R. (2010). Características e gastos com alimentação fora do domicílio no Brasil. Rev Saúde Pública, 44(2), 221-9.

Bezerra, I. N., Souza, A. M. Pereira, R. A., \& Sichieril, R. (2013). Consumo de alimentos fora do domicílio no Brasil. Rev Saúde Pública, 47(1Supl), 200S-11S.

Blackwell, R. D.; Miniard, P. W.; Engel, J. F. (2005). Comportamento do consumidor. São Paulo: Pioneira Thomson Learning.

BRASIL. Decreto $n$ ‥ 11.787, de 27 de novembro de 2003. Regulamenta a Lei no 5.949, de 16 de julho de 2003, que criou o Programa de Feiras Comunitárias Regionais do Município de Vitória e dá outras providências. 
Cardoso, R. D. C. V., Santos, S. M. C. D., \& Silva, E. O. (2009). Comida de rua e intervenção: estratégias e propostas para o mundo em desenvolvimento. Cien Saude Colet, 14(4), 1215-1224.

Castro, O. B. (2008). Uma leitura sobre alimentos seguros em restaurantes populares de Salvador. Escritas e narrativas sobre alimentação e cultura, 149173.

Cho, K., Park, S., \& Joo, N. (2011). Study on a model of street vended food choices by Korean high school students. Nutrition research and practice, 5 (5), 481-488.

Cortina, J. M. (1993). What is coefficient alpha? An examination of theory and applications. Journal of applied psychology, 78(1), 98.

De Moura, F. A., Nogueira, C. M., \& Gouvêa, M. A. (2012). Atributos determinantes na decisão de compra de consumidores de alimentos orgânicos. Agroalimentaria, 18(35), 75-86.

Edwards, J. S., Hartwell, H. J., \& Brown, L. (2013). The relationship between emotions, food consumption and meal acceptability when eating out of the home. Food Quality and Preference, 30(1), 22-32.

Ehsan, U. (2012). Factors important for the selection of fast food restaurants: an empirical study across three cities of Pakistan. British Food Journal, 114 (9), 1251-1264.

Fantinel, A. L., Teixeira, J. M. C., \& Ghizzo, M. R. (2011). O consumo de restauração fora de casa: uma amostra de indivíduos como parâmetro analítico. Revista Percurso, 3(1), 193-205.

FAO (2011). Food and Agriculture Organization. Disponível em: <http://www.fao.org/docrep/014/a1124p/a1124p.pdf>. Acesso em: 10 out. 2014.

Diez Garcia, R. W. (2003). Reflexos da globalização na cultura alimentar: considerações sobre as mudanças na alimentação urbana. Rev. Nutr, 16(4), 483-492.

Griffin, J. (1998). Como conquistar e manter o cliente fiel: transforme seus clientes em verdadeiros parceiros. São Paulo: Futura.
Hair Jr, J. F.; Black, W. C, Babin B. J. Anderson, R. E. \& Tatham, R. L. (2005). Análise multivariada de dados. 5. ed. Porto Alegre: Bookman.

Harrington, R. J., Ottenbacher, M. C., \& Kendall, K. $W$. (2011). Fine-dining restaurant selection: Direct and moderating effects of customer attributes.Journal of Foodservice Business Research, 14(3), 272289.

Hawkins, D. I.; Mothersbaugh, D. L. \& Best, R. J. (2007). Comportamento do consumidor: construindo a estratégia de marketing. 10. ed. Rio de Janeiro: Elsevier.

IBISWORLD (2014). Street Vendors in the US: Market Research Report. Recuperado em 27 de mar, 2015, de http://www.ibisworld.com/industry/default.aspx?indid=1683.

Karsaklian, E. (2004). Comportamento do consumidor. 2. ed. São Paulo. Atlas.

Lambert, J. L., Batalha, M. O., Sproesser, R. L., Silva, A. L. D., \& Lucchese, T. (2005). As principais evoluções dos comportamentos alimentares: o caso da França. Revista de Nutrição, 18(5), 577-591.

Leal, D. (2010). Crescimento da alimentação fora do domicílio. Segurança Alimentar e Nutricional, 17, 133-143.

Levine, D.M.; Stephan, D.F.; Krehbiel, T.C. \& Berenson, M.L. (2012). Estatística: Teoria e Aplicações (6a Edição). Livros Técnicos e Científicos Editora, Rio de Janeiro.

Lima Filho, D. O; Maia, F. S.; Mantovani, D. \& Arakaki, R. (2004) Comportamento Alimentar do Consumidor Idoso In: EnANPAD - Encontro da Associação Nacional de Pós-Graduação e Pesquisa em Administração (Evento Nacional), Anais, 2004.

Liu, M., Kasteridis, P., \& Yen, S. T. (2013). Breakfast, lunch, and dinner expenditures away from home in the United States. Food Policy, 38, 156-164.

Liu, Y., \& Jang, S. S. (2009). Perceptions of Chinese restaurants in the US: what affects customer satisfaction and behavioral intentions? International Journal of Hospitality Management, 28(3), 338-348. 
Machado, M. D., Queiroz, T. R., \& Martins, M. F. (2006). Mensuração da qualidade de serviço em empresas de fast food. Gestão \& Produção, 13(2), 261-270.

Malhotra, N. (2006) Pesquisa de Marketing: uma orientação aplicada. Trad. Laura Bocco. Porto Alegre: Bookman.

Mauro, Paulo César. (2013) Fast casual: a revolução na área de alimentação. Portal do Franchising. Recuperado em 15 de mar, 2015, de http://www.portaldofranchising.com.br/artigos-sobre-franchising/fast-casual-a-revolucao-na-area-de-alimentacao.

MacMillan, I. C., \& McGrath, R. G. (1996). Discover your products' hidden potential. Harvard Business Review, 74(3), 58.

Mhlanga, O., Hattingh, Z. \& Moolman, H.J. (2014). The effect of restaurant attributes on customers' expectations and experiences in formal full servisse restaurants in Port Elizabeth, South Africa. African Journal of Hospitality, Tourism and Leisure, 3(1).

Mowen, J. C. \& Minor, M. S. (2003). Comportamento do consumidor. São Paulo: Prentice Hall.

Muller, C. C., \& Woods, R. H. (1994). An expanded restaurant typology. Cornell Hospitality Quarterly, 35(3), 27.

Muyanja, C., Nayiga, L., Brenda, N., \& Nasinyama, G. (2011). Practices, knowledge and risk factors of street food vendors in Uganda. Food Control,22(10), 1551-1558.

Namkung, Y., \& Jang, S. (2007). Does food quality really matter in restaurants? Its impact on customer satisfaction and behavioral intentions.Journal of Hospitality \& Tourism Research, 31(3), 387-409.

Newman, L. L., \& Burnett, K. (2013). Street food and vibrant urban spaces: lessons from Portland, Oregon. Local Environment, 18(2), 233-248.

Nordström, J., \& Thunström, L. (2015). The impact of price reductions on individuals' choice of healthy meals away from home. Appetite, 89, 103-111.

Park, C. (2004). Efficient or enjoyable? Consumer values of eating-out and fast food restaurant con- sumption in Korea. International Journal of Hospitality Management, 23(1), 87-94.

Pelissari, A. S., de Oliveira, A. R., Gonzalez, I. V. D. P., Fabrini, M. F., \& da Silveira, R. C. (2011). Determinantes da satisfação dos clientes: Estudo de caso em uma loja de departamentos. Revista de Administração da Unimep-Unimep Business Journal, 32-48.

Peter, J. P. \& Olson, J. C. Comportamento do consumidor e estratégia de marketing. 8. ed. São Paulo: McGraw-Hill, 2009.

Pigatto, G. \& Nishimura, J. R. (2012). O Perfil do Empreendedor no Serviço de Alimentação de Rua. In: Encontro Nacional de Engenharia de Produção, 2012, Bento Gonçalves. XXXII Encontro Nacional de Engenharia de Produção.

Piza, P. T. (2014). Capital da gastronomia', SP agora aposta no sucesso dos 'food trucks'. G1. Recuperado em 20 dez, 2014, de_http://g1.globo.com/saopaulo/noticia/2014/03/capital-da-gastronomia-spagora-aposta-no-sucesso-dos-food-trucks.html.

Rane, S. (2011). Street vended food in developing world: hazard analyses.Indian journal of microbiology, 51(1), 100-106.

Reis, L. (2007). Relacionamento a longo prazo com os clientes. Em Questão,10(2), 405-418.

Rezende, C. D., \& Alberto Rodrigues Silva, M. (2013). Eating-out and experiential consumption: a typology of experience providers. British Food Journal, 116(1), 91-103.

Samapundo, S., Climat, R., Xhaferi, R., \& Devlieghere, F. (2015). Food safety knowledge, attitudes and practices of street food vendors and consumers in Port-au-Prince, Haiti. Food Control, 50, 457-466.

Sanches, M., \& Salay, E. (2011). Alimentação fora do domicílio de consumidores do município de Campinas, São Paulo. Rev. nutr, 24(2), 295-304.

Santos, K. B. O comércio da comida de rua no carnaval de Salvador-BA: desvendando as dimensões social, econômica, alimentar e sanitária. Dissertação (Mestrado em Alimentos, Nutrição e Saúde) Pro- 
grama de Pós-Graduação da Escola de Nutrição, Universidade Federal da Bahia, Salvador/BA, 2011.

Schlindwein, M. M., \& Kassouf, A. L. (2007). Influência do custo de oportunidade do tempo da Mulher sobre o padrão de consumo alimentar no Brasil. Pesquisa e Planejamento Econômico, 37, 489-520.

Schlindwein, M. M., \& Silva, A. B. M. (2010). Gasto domiciliar com alimentos: uma análise para a $\mathrm{Re}$ gião Centro-Oeste. Informe Gepec, 14(2), 129-48.

Siebeneichler, T., Wienningkamp, D., Ruchel, A. P., Trombini, E. S., \& Zamberlan, L. (2013). A Satisfação de Clientes de Restaurantes: Uma Avaliação da Satisfação e da Importância dos Atributos. Revista de Administração, 6(11), p-39.

Simon, G. (2013). Conceito consolidado, 'street food' fatura milhões de dólares nos Estados Unidos. Folha de São Paulo. [São Paulo, BR]. Recuperado em 10 de out, 2013, de http://www1.foIha.uol.com.br/comida/2013/09/1340115-conceito-consolidado-street-food-fatura-milhoes-dedolares-nos-estados-unidos.shtml.

Soriano, R. D. (2002). Customers' expectations factors in restaurants: The situation in Spain. International Journal of Quality \& Reliability Management, 19(8/9), 1055-1067.

Souki, G. Q., Madureira, K. T., Gonçalves Filho, C., \& Neto, M. T. R. (2010). Desenvolvimento e Validação de uma Escala de Atributos Utilizados pelos Consumidores na Escolha de Restaurantes de Comida a Quilo. DOI: 10.15600/1679-5350/rau. v8n2p7290. Revista de Administração da Unimep-Unimep Business Journal, 8(2), 72-90.

Taplin, R. H. (2012). The value of self-stated attribute importance to overall satisfaction. Tourism Management, 33(2), 295-304.

Vergara, S. C. (2011). Projetos e relatórios de pesquisa em administração. 13. ed. São Paulo: Atlas. Vieira, V. A., \& Slongo, L. A. (2008). Uma análise dos atributos importantes no processo de decisão de compra de notebooks utilizando análise fatorial e escalonamento multidimensional. Revista de Administração Mackenzie, 7(4).
WHO. (1996). Division of Food and Nutrition. Essential safety requirements for street-vended foods (Revised Edition). Recuperado em 29 de out, 2013, de http://www.who.int/foodsafety/publications/fs_management/en/streetvend.pdf.

Zeithaml, V. A. (1988). Consumer perceptions of price, quality, and value: a means-end model and synthesis of evidence. The Journal of marketing, 52 (2), 2-22.

\section{Dados dos autores}

\section{Hannah Nicchio Loriato}

Universidade Federal do Espírito Santo. Mestrado em administração pela Universidade Federal do Espírito Santo (UFES), Distrito Federal. E-mail: hannahnl@gmail.com

\section{Anderson Soncini Pelissari}

Professor do Departamento de Administração da UFES (Universidade Federal do Espírito Santo). Professor do Programa de Pós-graduação em Administração - Mestrado e Doutorado - PPGADM/UFES e Pesquisador do TecPrO/UFES. Doutor em Engenharia de Produção pela Universidade Metodista de Piracicaba. Pesquisador nas áreas de Estratégias de Marketing e de Negócios - Grupo de Estudos em Marketing e Estratégia (GEMaE). E-mail: asoncinipelissari@gmail.com 